\section{Service spotlight: Dr John Best and the injury clinic for asylum seekers and refugees}

\author{
Mohammad Chaker Jomaa (1)
}

Dr John Best is one of Australia's leading sports and exercise medicine physicians. He has had a successful career for many years since being awarded his fellowship with the Australasian College of Sports and Exercise Physicians in 1992. He has worked in various elite sporting roles, including the Australian rugby (Wallabies) team between 1994 and 2000, being part of their 1999 World Cup victory. Dr Best was awarded the Australian Sports Medal for his contribution to sports medicine in 2000. He currently acts as a medical consultant to the Australian Professional Golfers' Association tournaments and is on the Australian National Rugby League Medical Advisory Panel.

\section{A SPORT AND EXERCISE MEDICINE CLINIC FOR REFUGEES WAS BORN}

In 2017, Dr Best set up the Injury Clinic for Asylum Seekers and Refugees (ICFAR) in Western Sydney, Australia. Since its opening, the clinic has operated once every 2 weeks, serving the local disadvantaged refugee and asylum seeker communities. Patients from Sri Lanka, Syria, Afghanistan, Iran and beyond have all presented with a range of medical ailments, acute and chronic musculoskeletal injuries and sociopolitical concerns.

Dr Best volunteers his time to support the refugee community through this clinic; bringing them care, compassion, a platform to be heard, and the highest levels of specialist sport and exercise medicine treatment. Additionally, he also volunteers this time out to his registrars in specialist training, affording them opportunities for direct supervision, mentoring and teaching at the clinic.

\section{THE CHALLENGES FACED BY THE COMMUNITY}

Musculoskeletal injuries among asylum seekers will often present at an advanced

School of Public Health, University of Sydney, Sydney Medical School, Sydney, New South Wales, Australia

Correspondence to Dr Mohammad Chaker Jomaa, School of Public Health, University of Sydney, Sydney Medical School, Sydney 2050, New South Wales, Australia; moe.jomaa@gmail.com stage. Patients as young as $30-40$ years of age have presented to the clinic with severe degenerative osteoarthritis and chronic major joint instability. Additionally, injury presentations are often compounded by psychosocial problems.

Sadly, for many asylum seekers, the journey to Australia is often fraught with danger and for the vast majority, the arrival invariably involves a period of (often prolonged) detention. Patients may be recovering from vivid traumatic experiences from their homeland, the treacherous journey and from assaults sustained while in detention. These traumas remain with them and intensify their suffering, leading to disturbed sleep, reduced quality of life and very often, chronic pain.

\section{ENORMOUS IMPACT ON THE REFUGEE COMMUNITY}

At ICFAR, patients have access to otherwise unattainable specialist sports medical care. Education, rehabilitation and exercise

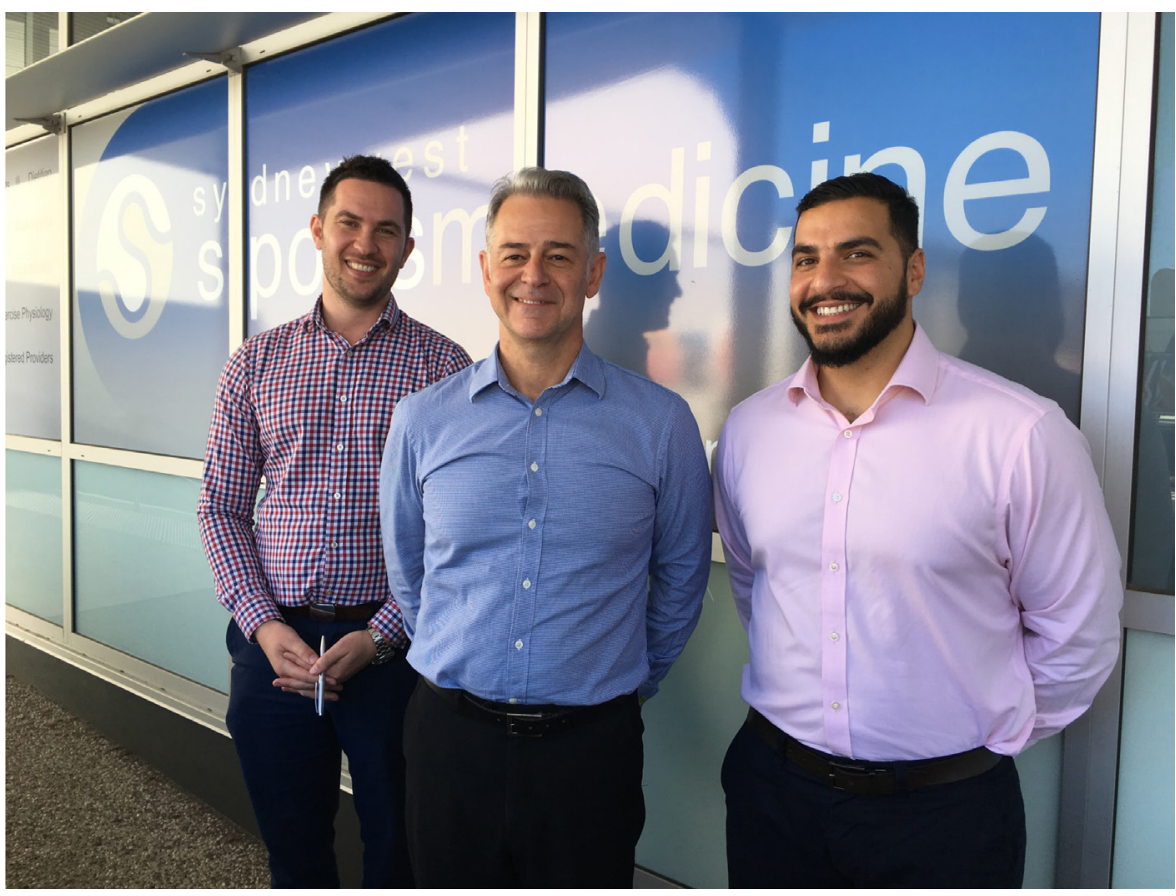

Figure 1 Dr Best (centre) standing outside of Sydney West Sports Medicine Clinic, where the Injury Clinic for Asylum Seekers and Refugees, is held. Alongside are two of his registrars: Dr Leigh Golding (left) and Dr Mohammad Jomaa (right). with severe bilateral knee osteoarthritis, varus knee deformities and a profound varus thrust that left him unable to walk without a stick. Mr GB suffered from chronic pain and depression secondary to his ailment when presenting to Dr Best. His case was discussed by Dr Best with local surgeons and bilateral total knee replacement surgery was arranged. Today, Mr GB is progressing through a comprehensive exercise and rehabilitation programme following surgery. $\mathrm{He}$ has corrected knee alignment, reduced pain and improved function, and reports feeling more confident and positive in his outlook. In reference to Dr Best and ICFAR, "I cannot thank him enough," he said, "he has changed the course of my life."

\section{WORKING TO ENSURE A SUSTAINABLE PROJECT}

In addition to providing access to highquality sports medical care for the local refugee communities, Dr Best has set up ICFAR as a safe hub for members of the programmes are commonly prescribed alongside therapeutic interventions, such as ultrasound-guided injections. In instances where more interventional care is warranted, Dr Best discusses cases with local surgeon contacts, who are happy to offer their consultation and surgical services to the cause.

A recent example of the positive impact of Dr Best's work on others was the case of Mr GB, a 40-year-old man who presented 


\section{Service spotlight}

community to share their struggles. Many refugees are unable to acquire the sense of security that is afforded by a visa. They report feeling trapped and in limbo, being left without the right to work, to study or even to acquire a Medicare card, necessary in order to access essential healthcare in Australia. As such, ICFAR has grown to recognise the plight of loneliness, loss of identity and the frustrations suffered by the communities it serves.

Through his initiative, health advocacy and intervention, Dr Best is proving how the sports and exercise medicine specialty is suited to support the lifestyle challenges, chronic pain and healthcare needs for some of Australia's disadvantaged communities. "I'm very fortunate," Dr Best reflects, "I've never had a bad day at work."

Looking ahead, a sustainable model of care must be considered. Without the generosity of Dr Best (who volunteers his time for free) and Sydney West Sports Medicine Clinic (which kindly hosts the clinic at no profit (figure 1)), the ICFAR clinic could not exist. By reflecting on Dr Best's impact through ICFAR, we can ignite an important conversation around the role that sport and exercise medicine clinicians have in the care of our disadvantaged communities.

\section{CONTACTS OR RESOURCES FOR MORE INFORMATION ABOUT THE SERVICE OR PROGRAMME}

For more information and further contact details, please visit the clinic's Facebook page at https://www.facebook.com/ ICFAR/.

Twitter Mohammad Chaker Jomaa @moefriday

Contributors The article author is MCJ. Styling and grammatical editing assistance provided by Dr Joanne Kemp and Dr Andrea Mosler.
Funding The authors have not declared a specific grant for this research from any funding agency in the public, commercial or not-for-profit sectors.

Competing interests None declared.

Patient consent for publication Not required.

Provenance and peer review Not commissioned; externally peer reviewed.

Data availability statement No data are available.

(C) Author(s) (or their employer(s)) 2021. No commercial re-use. See rights and permissions. Published by BMJ.

\section{(A) Check for updates}

To cite Chaker Jomaa M. Br J Sports Med 2021:55:935-936.

Accepted 12 April 2021

Published Online First 21 April 2021

Br J Sports Med 2021;55:935-936. doi:10.1136/bjsports-2021-104282

ORCID iD

Mohammad Chaker Jomaa http://orcid.org/0000-00017916-2755 